\title{
BARREIRAS SANITÁRIAS E PROTECIONISMO NO CONTEXTO DA ORGANIZAÇÃO MUNDIAL DO COMÉRCIO
}

\author{
Natália Paulino Bonnomi ${ }^{1}$
}

\begin{abstract}
Resumo
$\mathrm{O}$ artigo aborda o disciplinamento de barreiras comerciais sanitárias pela OMC, cuja proliferação pode se tornar ainda mais acentuada em face da atual crise sanitária decorrente da COVID-19. Diante disso, o artigo objetiva explorar os critérios estabelecidos pela OMC para reconhecer a legitimidade de políticas sanitárias em face das regras de livre comércio, em especial a partir da análise do Artigo XX do GATT e do Acordo SPS. Concluiu-se que tais Acordos garantem o direito dos Membros da OMC de implementar políticas sanitárias, desde que respeitados critérios que demonstrem a sua legítima finalidade.
\end{abstract}

Palavras-chave: Saúde. Barreiras não-tarifárias. Comércio internacional. Protecionismo. OMC.

\section{SANITARY BARRIERS AND PROTECTIONISM IN THE CONTEXT OF THE WORLD TRADE ORGANIZATION}

\begin{abstract}
The article addresses the WTO disciplines on sanitary trade measures, whose proliferation may grow in light of the current health crisis caused by the COVID-19. The article then aims to explore the criteria determined by the WTO to recognize the legitimacy of sanitary policies in view of free trade rules, specially regarding Article XX of the GATT and the SPS Agreement. It was concluded that those Agreements guarantee the right of WTO Members of adopting measures aiming at human health protection, as long as some requirements are met to demonstrate their legitimate purpose.
\end{abstract}

Keywords: Human health. Non-tariff barriers. International trade. Protectionism. WTO.

\section{Introdução}

Os Estados têm estabelecido padrões rigorosos para evitar que produtos domésticos e importados contenham agentes prejudiciais à saúde de sua população. Nesse cenário, cada vez mais essas normas sanitárias têm afetado o comércio internacional e gerado uma preocupação acerca da possibilidade de essas normas serem utilizadas com uma finalidade protecionista.

\footnotetext{
${ }^{1}$ Doutoranda e Mestre em Direito no Programa de Pós-Graduação em Direito da Universidade Federal de Pernambuco (PPGD/UFPE). Advogada. E-mail: nataliapbmi@gmail.com.
} 
Há uma tendência, em especial no momento pandêmico que vivemos em razão da COVID-19, de que as normas sanitárias se tornem ainda mais rígidas de modo a evitar a proliferação transnacional de doenças, o que pode afetar o fluxo comercial entre países. No entanto, embora essas normas visem a um interesse público legítimo, em princípio, elas podem disfarçar uma intenção protecionista do Estado importador.

Sendo assim, a OMC exerce um papel de governança relevante no que concerne às barreiras não-tarifárias, inclusive as medidas sanitárias. Em face da complexidade de eventuais obstáculos impostos por essas medidas, há uma dificuldade de se mensurar até que ponto esses padrões de proteção são adotados pelo interesse público ou se constituem novas formas de protecionismo no comércio internacional (KOTZIAS; THORSTENSEN, 2015, p. 82).

Diante disso, faz-se necessário compreender as regras que disciplinam as medidas sanitárias no âmbito do comércio internacional. O principal objetivo deste artigo é demonstrar quais os critérios, designados pela Organização Mundial do Comércio (OMC), para justificar a legitimidade de medidas sanitárias e, assim, evitar que estas sejam adotadas com um intuito protecionista.

Para tanto são abordados os acordos da OMC que regulamentam medidas sanitárias que representam barreiras comerciais. $\mathrm{O}$ artigo examina o tema sob a perspectivo do Acordo Geral de Tarifas e Comércio (GATT), em particular seu Artigo XX(b), e do Acordo sobre a Aplicação de Medidas Sanitárias e Fitossanitárias (Acordo SPS). O artigo também analisa esses dispositivos segundo a interpretação conferida pelo sistema de solução de controvérsias da OMC.

Na primeira seção, são estudados os principais aspectos que envolveram a formação do Artigo XX do GATT, que constitui hipóteses de exceções gerais às obrigações dispostas no Acordo. Ainda na primeira seção, é analisada a disputa $E C$ - Asbestos, cuja resolução expõe os entendimentos fulcrais acerca da aplicação do Artigo XX(b), que coloca políticas sanitárias na lista de exceções gerais.

Na segunda seção, são apresentadas as principais normas do Acordo SPS, em especial no que se refere à proteção da saúde e vida humana. Nessa seção, é abordado o caso EC Hormones, em que o Órgão de Apelação confere a interpretação a determinados dispositivos do Acordo SPS. 
A pesquisa realizada neste artigo esclarece o entendimento da OMC sobres os limites ao direito de seus Membros de adotar políticas sanitárias. Sendo assim, o artigo mostra os critérios apontados pela Organização, sob os fundamentos do Artigo XX(b) do GATT e do Acordo SPS, para garantir o equilíbrio entre o legítimo interesse de salvaguardar a saúde da população e o interesse econômico.

\section{GATT}

\subsection{Histórico do Artigo XX do GATT}

O GATT foi um acordo negociado, inicialmente, por vinte e três Estados após o fim da Segunda Guerra Mundial. O objetivo do Acordo era liberalizar o comércio até a criação da Organização Internacional do Comércio (OIC), que decorreria da Carta de Havana de 1948. O documento estabelece os princípios basilares do atual sistema multilateral de comércio, mas suas negociações cessaram, em particular, porque os Estados Unidos temiam que a OIC prejudicasse o exercício de sua soberania.

Embora a OIC não tenha sido constituída, o GATT deu ensejo a diversas rodadas de negociação até o surgimento da OMC em 1994, que continua sendo guiada, em grande parte, pelo GATT de 1947. Mesmo em sua redação original, o GATT já previa um mecanismo de flexibilização de suas regras em virtude de interesses não-econômicos, consubstanciado em seu Artigo XX (AMARAL JÚNIOR et al., 2009, p. 26).

Em 1994, no fim da Rodada Uruguai e com o surgimento da OMC, as exceções ao livre comércio previstas no Artigo XX do GATT não pareciam ter o mesmo cunho retórico de outrora ainda que o seu texto fosse semelhante. As exceções representavam certa primazia de valores não-comerciais, que poderiam afastar a aplicação de normas comerciais orientadoras do GATT diante de sua divergência, nos termos das alíneas e do caput do dispositivo. O objetivo do Artigo XX do GATT foi o de manter uma margem de policy space dos Estados contratantes a fim de proteger interesses públicos considerados sensíveis às políticas domésticas (VIEIRA, 2014, p. 51).

Desta feita, a OMC tem demonstrado que procura aliar o seu objetivo precípuo de liberalização do comércio ao direito dos Estados de implementar políticas de proteção a interesses sensíveis da população, como a saúde humana. Nesse sentido, o Artigo XX do GATT funciona como um instrumento de exceção às regras comerciais diante de medidas 
voltadas a interesses não-econômicos que, caso não tivessem tal objetivo legítimo, seriam consideradas barreiras injustificadas ao comércio internacional (MOROSINI; NIENCHESKI, 2014, p. 161-162). O Artigo XX do GATT assim se encontra redigido:

\section{ARTIGO XX \\ EXCEÇÕES GERAIS}

Desde que essas medidas não sejam aplicadas de forma a constituir quer um meio de discriminação arbitrária, ou injustificada, entre os países onde existem as mesmas condições, quer uma restrição disfarçada ao comércio internacional, disposição alguma do presente capítulo será interpretada como impedindo a adoção ou aplicação, por qualquer Parte Contratante, das medidas:

(a) necessárias à proteção da moralidade pública;

(b) necessárias à proteção da saúde e da vida das pessoas e dos animais e à preservação dos vegetais;

(c) que se relacionem à exportação e a importação do ouro e da prata;

(d) necessárias a assegurar a aplicação das leis e regulamentos que não sejam incompatíveis com as disposições do presente acordo, tais como, por exemplo, as leis e regulamentos que dizem respeito à aplicação de medidas alfandegárias, à manutenção em vigor dos monopólios administrados na conformidade do $\S 4^{\circ}$ do art. II e do art. XVII à proteção das patentes, marcas de fábrica e direitos de autoria e de reprodução, e a medidas próprias a impedir as práticas de natureza a induzir em erro;

(e) relativas aos artigos fabricados nas prisões:

(f) impostas para a proteção de tesouros nacionais de valor artístico, histórico ou arqueológico;

(g) relativas à conservação dos recursos naturais esgotáveis, se tais medidas forem aplicadas conjuntamente com restrições à produção ou ao consumo nacionais;

(h) tomadas em execução de compromisso contraídos em virtude de um Acordo intergovernamental sobre um produto de base, em conformidade com os critérios submetidos às Partes Contratantes e não desaprovados por elas e que é ele próprio submetido às Partes Contratantes e não é desaprovado por elas.

(i) que impliquem em restrições à exportação de matérias primas produzidas no interior do país e necessárias para assegurar a uma indústria nacional de transformação as quantidades essenciais das referidas matérias-primas durante os períodos nos quais o preço nacional seja mantido abaixo do preço mundial, em execução de um plano governamental de estabilização; sob reserva de que essas restrições não tenham por efeito reforçar a exportação ou a proteção concedida à referida indústria nacional e não sejam contrárias às disposições do presente Acordo relativas à não discriminação.

(j) essenciais à aquisição ou a distribuição de produtos dos quais se faz sentir uma penúria geral ou local; todavia, as referidas medidas deverão ser compatíveis com o princípio segundo o qual todas as Partes Contratantes têm direito a uma parte equiitativa do abastecimento internacional desses produtos e as medidas que são incompatíveis com as outras disposições do presente Acordo serão suprimidas desde que as circunstâncias que as motivaram tenham deixado de existir. As Partes Contratantes examinarão, em 30 de junho de 1960, no máximo, se é necessário manter a disposição da presente alínea.

No que diz respeito ao estudo desenvolvido neste artigo, o Artigo XX do GATT inclui expressamente a proteção da saúde e da vida humana. Nesse sentido, o Artigo XX(b) autoriza 
os Membros da OMC a adotar medidas necessárias à proteção da saúde e da vida das pessoas sem que incorram em violação das obrigações do GATT.

Embora o Artigo XX do GATT reconheça o direito dos Membros de implementar políticas sanitárias, por exemplo, este direito não é absoluto, visto que seu exercício é limitado à necessidade da medida e às regras do caput do Artigo XX. $\mathrm{O}$ citado dispositivo estabelece, em seu caput, que as medidas não podem ser aplicadas de modo a constituir uma discriminação arbitrária ou injustificável entre países onde as mesmas condições prevalecem, bem como não podem ser empregadas de forma a se impor uma restrição disfarçada ao comércio.

Para que possam ser explanados os critérios para a aplicação do Artigo XX(b) do GATT, o artigo debruça-se sobre a interpretação do dispositivo conferida pelo sistema de solução de controvérsias da OMC. Com essa finalidade, o artigo seleciona a disputa $E C$ Asbestos, emblemático por ter reconhecido a justificação da medida diante do Artigo XX(b), para averiguar tais critérios.

\subsection{Interpretação do Artigo XX(b) do GATT}

O caso EC - Asbestos foi submetido à OMC pelo Canadá em razão de uma medida francesa de banimento de fibras de amianto em virtude do risco de causarem câncer de pulmão e mesoteliomas a quem as manipulasse. De acordo com o Canadá, no que se refere ao GATT, a medida adotada pela França violara a obrigação de eliminação de restrições quantitativas (Artigo XI:1) e a obrigação de tratamento nacional (Artigo III:4). A União Europeia rebateu tais argumentos e acrescentou que a medida era necessária para proteger a saúde humana, nos termos do Artigo XX(b) do GATT.

O relatório do Panel, ao analisar a aplicabilidade do Artigo XX do GATT à disputa, afirmou que primeiro deve-se examinar se a medida controvertida está abarcada pelo parágrafo (b) do Artigo XX e, em caso positivo, se a medida satisfaz os requisitos previstos no caput do Artigo XX. Quanto à análise de consistência da medida com o Artigo XX(b), primeiro deve-se demonstrar se a medida consiste em uma política de proteção à saúde ou 
vida humana, para depois averiguar se a medida se mostra de fato necessária para alcançar tal objetivo $^{2}$.

No caso em apreço, o objetivo a ser alcançado pela medida francesa era a proteção de trabalhadores e consumidores diante dos riscos à saúde causados pelo amianto. O Canadá não negou a legitimidade desse objetivo, contudo afirmou que a fibra de amianto crisotila, quando aplicada de forma controlada e segura, não oferecia risco à saúde humana ${ }^{3}$. O Panel considerou que as evidências colacionadas ao caso demonstravam que o amianto apresentava um risco à saúde humana, pelo que concluiu que a medida francesa era consistente com uma política de proteção à saúde ou vida humana, nos termos do Artigo XX(b) do GATT ${ }^{4}$.

O Panel partiu, então, para a segunda etapa da sua análise de consistência de uma medida com o Artigo XX(b) do GATT, qual seja, verificar se a medida controvertida é necessária para atingir o seu objetivo. O Panel, reforçando o entendimento adotado no caso Thailand - Cigarettes, estabeleceu que a medida será necessária, para fins do Artigo XX(b), quando não houver medidas alternativas consistentes com o GATT ou menos inconsistentes. Nesse sentido, o Canadá alegou haver medidas alternativas para alcançar o objetivo almejado pela medida francesa, como o uso controlado do amianto, a proteção de vias aéreas e a adoção métodos de descontaminação de equipamentos e uniformes de trabalho ${ }^{5}$.

Diante das alternativas apresentadas pelo Canadá, o Panel avaliou se tais medidas seriam suficientemente efetivas para atingir o objetivo da medida controvertida, bem como se constituiriam medidas razoavelmente disponíveis. A análise do Panel, nesse sentido, apontou que as medidas alternativas apresentadas não eram efetivas ou razoavelmente disponíveis, em particular quanto ao setor de construção e trabalhadores informais, o que demonstrava a necessidade da medida controvertida, nos termos do Artigo XX(b) do GATT ${ }^{6}$.

Após considerar que a medida francesa cumprira os requisitos do parágrafo (b) do Artigo XX do GATT, o Panel passou a averiguar se a medida estava em conformidade com o caput do Artigo XX. Para iniciar essa análise, o Panel observou se aplicação da medida controvertida era arbitrária ou injustificadamente discriminatória ${ }^{7}$.

${ }^{2}$ WORLD TRADE ORGANIZATION. European Communities - Measures Affecting Asbestos and Asbestos-Containing Products, Panel Report, WT/DS135/R and Add.1, adopted 5 April 2001, as modified by Appellate Body Report WT/DS135/AB/R, DSR 2001:VIII, p. 3305, par. 8.167-8.169.

3 Ibidem, par. 8.173.

${ }^{4}$ Ibidem, par. 8.193-8.194.

${ }^{5}$ Ibidem, par. 8.198; 8.204.

${ }^{6}$ Ibidem, par. 8.208; 8.217.

${ }^{7}$ Ibidem, par. 8.226. 
Nesse sentido, o Panel verificou que a medida não apresentava discriminação acerca do país de origem do produto, inclusive da própria França. Além disso, o Canadá não ofereceu qualquer argumento que demonstrasse a ocorrência de discriminação na prática. Sendo assim, o Panel considerou que não houve discriminação no caso em comento, nos termos do caput do Artigo XX do GATT ${ }^{8}$.

No que diz respeito à segunda parte do caput do Artigo XX, o Panel debruçou-se sobre a interpretação da expressão "restrição disfarçada ao comércio". O Panel observou que essa expressão não havia sido definida de forma clara e recordou de antigos casos do GATT em que se atrelava o termo a uma restrição que não teria tomado a forma de uma medida comercial ou não teria sido previamente anunciada ou, ainda, que não teria sido objeto de publicação ou de investigação ${ }^{9}$.

O Panel aduziu, no entanto, que tal interpretação à expressão era muito restrita. Com base no entendimento do Órgão de Apelação sobre o tema, o Panel afirmou que, para que uma medida seja considerada uma restrição disfarçada ao comércio, seria necessário demonstrar que esta apenas formalmente teria um objetivo legítimo nos termos de um dos parágrafos do Artigo XX (proteção à saúde e vida humana, por exemplo), mas disfarçaria o seu real objetivo de restrição ao comércio ${ }^{10}$.

No caso em apreço, o Panel não identificou qualquer objetivo protecionista na medida francesa ao analisar sua forma, arquitetura e estrutura. Em verdade, o Panel constatou que e medida de banimento da importação de amianto não beneficiou a indústria francesa de fibras substitutas em detrimento de produtores estrangeiros, o que corroborou para sua conclusão de que a medida não constituiria uma restrição disfarçada ao comércio internacional. Consequentemente, o Panel concluiu que a medida controvertida estava conforme aos requisitos do caput do Artigo XX do GATT ${ }^{11}$.

Após uma breve análise do caso EC - Asbestos no que concerne à aplicação do Artigo $\mathrm{XX}$ (b) do GATT, é possível observar que há requisitos rigorosos para que uma medida seja considerada conforme ao dispositivo. Como exposto, nesse juízo de conformidade deve-se verificar, primeiro, se a medida controvertida constitui uma política prevista em algum dos

\footnotetext{
${ }^{8}$ Ibidem, par. 8.228-8.229.

${ }^{9}$ Ibidem, par. 8.233 .

${ }^{10}$ Ibidem, par. 8.235-8.236.

${ }^{11}$ Ibidem, par. 8.239-8.240.
} 
parágrafos do Artigo XX, no caso deste estudo, se a medida tem o propósito de proteger a saúde humana; e se a medida é necessária para alcançar tal objetivo.

$\mathrm{O}$ teste de necessidade estabelecido pelo Artigo XX(b) do GATT envolve, inicialmente, a análise acerca da compatibilidade entre a medida sanitária e o objetivo almejado, no caso, a proteção da saúde humana. Além disso, de acordo com a interpretação conferida pelo sistema de solução de controvérsias da OMC ao Artigo XX(b) do GATT, o teste de necessidade engloba, ainda, uma avaliação sobre o impacto restritivo da medida sanitária no comércio internacional, a partir da qual deve-se examinar a existência de possíveis medidas alternativas compatíveis com o $\mathrm{GATT}^{12}$.

Em segundo lugar, impõe-se a averiguação de conformidade da medida com o caput do Artigo XX. Tal análise tem por finalidade verificar se a medida foi aplicada ou não de forma arbitrária ou injustificadamente discriminatória ou, ainda, de modo a disfarçar uma restrição ao comércio internacional. O juízo de conformidade da medida em relação ao caput do Artigo XX do GATT diz respeito à sua forma de aplicação, se esta é aplicada independentemente da origem do produto e se é adotada com uma finalidade legítima, que não a de proteger setores domésticos.

Diante do exposto, observa-se que o GATT reconhece o direito dos Membros de adotar políticas regulatórias, dentre elas a sanitária, a fim de proteger interesses públicos legítimos. Entretanto, o GATT estabelece regras rígidas para evitar que os Membros abusem desse direito e dele se utilizem apenas como pretexto para, na prática, implementar medidas de cunho protecionista ou injustificadamente discriminatório.

\section{Acordo SPS}

\subsection{Histórico do Acordo SPS}

\footnotetext{
${ }^{12}$ Conforme esclarecido pelo Panel no caso Brazil - Retreaded Tyres, com fundamento em casos analisados pelo Órgão de Apelação, o teste de necessidade contido no Artigo XX(b) do GATT depende de um processo de ponderação de diversos fatores (weighing and balancing process), que normalmente perpassa três fatores: a importância dos interesses ou valores almejados pela medida; a contribuição da medida para alcançar o seu propósito; e o impacto restritivo da medida no comércio internacional. A partir daí, faz-se necessário uma comparação entre a medida controvertida e possíveis medidas alternativas para verificar se há uma alternativa consistente ou menos inconsistente com o GATT. Nesse sentido, ver: WORLD TRADE ORGANIZATION. Brazil - Measures Affecting Imports of Retreaded Tyres, Panel Report, WT/DS332/R, adopted 17 December 2007, as modified by Appellate Body Report WT/DS332/AB/R, DSR 2007:V, p. 1649, par. 7.104.
} 
Antes da Rodada Uruguai, que culminou com a institucionalização da OMC, alguns códigos eram negociados em base plurilateral, durante as Rodadas Kennedy e Tóquio, para regulamentar determinados tipos de barreiras comerciais não-tarifárias, cujas regras vinculavam apenas seus signatários. Após a Rodada Kennedy, cresceu a preocupação dos países contratantes do GATT acerca da harmonização de standards nacionais, o que ensejou a necessidade de sua regulamentação, em particular por meio de standards internacionais, para evitar o protecionismo. Ao final da Rodada Tóquio, foi concluído o Standards Code, que disciplinava especificações e regulamentos técnicos e standards para produtos agrícolas e industriais (MARCEAU; TRACHTMAN, 2014, p. 354-355).

Durante a Rodada Uruguai, houve um consenso no sentido de que o Standards Code havia falhado em seu objetivo de combater as distorções comerciais originadas no setor agrícola pela proliferação de restrições técnicas. Nesse cenário, com a implementação da OMC, o Standards Code foi suplantado por dois Acordos: o Acordo sobre Barreiras Técnicas (Acordo TBT) e Acordo sobre a Aplicação de Medidas Sanitárias e Fitossanitárias (Acordo SPS) (MARCEAU; TRACHTMAN, 2014, p. 355) ${ }^{13}$.

O Acordo TBT pretende garantir que os procedimentos concernentes à regulação, padrões, testes e certificações não criem obstáculos desnecessários ao comércio, permitindo aos Estados, contudo, que estes tomem medidas adequadas para a proteção da vida e da saúde de seres humanos, animais e vegetais. O referido Acordo aplicase a características do produto e aos métodos de processo e produção que tenham efeito sobre as suas características e qualidade, tendo como intuito garantir padrões de qualidade e de segurança (BARROS, G.S.A.C.; BURNQUIST, H.L.; CUNHA FILHO, J.H.; MIRANDA, S.H.G, 2004, p. 26-27).

Já o Acordo SPS é destinado a regulamentar as medidas referentes à vida ou à saúde humana, animal ou vegetal que afetem o comércio internacional. Embora o Acordo TBT toque superficialmente a proteção sanitária como política legítima apta a justificar uma medida em tese contrária às regras do Acordo, o presente artigo abordará exclusivamente o Acordo SPS. Isso porque o Acordo SPS estabelece normas de maior operacionalização e contém critérios mais claros para guiar o intérprete no sentido de averiguar se determinada política sanitária é conforme ou não ao Acordo.

\footnotetext{
${ }^{13}$ Nesse sentido, ver também: AMARAL JÚNIOR, Alberto do. Comércio internacional e a proteção do meio ambiente. São Paulo: Atlas, 2011, p. 170-173.
} 
o Acordo define como medidas sanitárias ou fitossanitárias aquelas aplicadas para proteger a vida ou a saúde humana, animal ou vegetal de riscos resultantes de pragas, doenças ou organismos patogênicos ou portadores de doenças; e para proteger a vida ou a saúde humana ou animal de riscos provenientes de aditivos, contaminantes, toxinas ou organismos patogênicos em alimentos, bebidas ou ração animal (Artigo 1 do Anexo A). O Acordo SPS é, portanto, voltado à regulamentação de medidas sanitárias e fitossanitárias (medidas SPS), aquelas que servem à proteção da vida ou saúde humana, animal ou vegetal.

O embasamento científico é essencial para justificar a adoção de medidas SPS. Nesse sentido, o Artigo 2.2 do Acordo SPS determina que as medidas SPS deverão ser adotadas de forma necessária a garantir a proteção almejada, baseada em princípios científicos, e não deverá ser mantida sem evidência científica suficiente para tanto. No entanto, o Artigo 5.7 do Acordo SPS autoriza os Membros a manter uma medida SPS provisoriamente, no caso de evidências científicas insuficientes, desde que estejam embasadas em informação pertinente disponível; nesse caso, o Membro deverá buscar a informação adicional necessária para uma avaliação mais objetiva do risco, e revisará a medida em um prazo razoável.

O Artigo 5.7 do Acordo SPS acendeu o debate em torno da aplicação do princípio da precaução no comércio internacional ${ }^{14}$. O referido princípio é largamente reconhecido no contexto do Direito Internacional do Meio Ambiente, e demanda cautela em face de um risco desconhecido de dano ao meio ambiente. O Artigo 5.7 parece refletir uma abordagem de precaução, mas sua interpretação no âmbito do sistema de solução de controvérsias da OMC, como será abordado no próximo tópico, demonstra que o princípio da precaução não rege o Acordo SPS de forma autônoma, mas sim de forma limitada aos termos dos seus dispositivos.

O Artigo 3 do Acordo SPS estabelece regras para a harmonização de medidas SPS, que é incentivada pelo Acordo por meio de normas, guias e recomendações internacionais, conforme o Artigo 3.1. Se a medida SPS estiver em conformidade com standards internacionais, o Artigo 3.2 do Acordo SPS reconhece a presunção de sua necessidade para a proteção da vida ou saúde humana, animal ou vegetal, bem como a sua compatibilidade com o Acordo e com o GATT.

\footnotetext{
14 Sobre o tema, ver: BONNOMI, Natália Paulino. O princípio da precaução no comércio internacional: confronto entre a proteção ambiental e o livre comércio. In: Eugênia Cristina Nilsen Ribeiro Barza; Francisco Antônio de Barros e Silva Neto; Paul Hugo Weberbauer. (Org.). Integração regional, globalização e direito internacional, vol. 2, 1ed. Recife: UFPE, 2019, p. 105-128.
} 
Já o Artigo 3.3 do Acordo SPS assegura o direito dos Membros da OMC de adotar medidas SPS que resultem em nível mais elevado de proteção sanitária ou fitossanitária do que se alcançaria com medidas baseadas em padrões internacionais. Nessa hipótese, exige-se uma justificação científica ou a demonstração do nível de proteção sanitária ou fitossanitária que um Membro determine ser apropriado, ambos os casos nos termos do Artigo 5 do Acordo SPS.

Por fim, o Artigo 5 do Acordo SPS dispõe sobre avaliação de risco e determinação do nível apropriado de proteção sanitária e fitossanitária. O Artigo 5.2 determina que, na avaliação de risco, os Membros levarão em consideração a evidência científica disponível, os processos e métodos de produção pertinentes, os métodos para teste, amostragem e inspeção pertinentes, a prevalência da pragas e doenças específicas, a existência de áreas livres de pragas ou doenças, condições ambientais e ecológicas pertinentes e os regimes de quarentena ou outros.

No que concerne ao nível apropriado de proteção sanitária e fitossanitária, o Artigo 5.4 do Acordo SPS estabelece que sua definição deve levar em conta o objetivo de reduzir ao mínimo os efeitos negativos ao comércio. Já o Artigo 5.5 determina que os Membros, ao determinar um nível apropriado de proteção, não devem estabelecer distinções que conduzam a uma discriminação arbitrária ou injustificada ou, ainda, a um protecionismo.

De uma forma mais sistemática, pode-se constatar que as medidas SPS devem estar baseadas em princípios científicos e não podem ser mantidas sem evidências científicas suficientes. No caso de as medidas não estarem de acordo com os padrões internacionais, que promovem a harmonização das medidas SPS, exige-se a avaliação de risco. O processo de avaliação deve levar em consideração, dentre outros aspectos, as evidências científicas disponíveis. No caso de sua insuficiência, pode ser adotada uma medida SPS, provisoriamente, com base nas informações pertinentes disponíveis; nesse caso, o Membro deverá buscar a obtenção de dados adicionais necessários para uma avaliação de risco mais objetiva (GRUSZCZYNSKI, 2006, p. 8-9).

\section{Interpretação do Acordo SPS}

A disputa EC - Hormones decorreu de uma reclamação contra as Comunidades Europeias acerca de Diretivas que estabeleciam a proibição de carne ou produtos derivados 
contendo determinados hormônios com fundamento na necessidade de proteger a saúde humana. O Panel concluiu que a medida europeia de restrição de importação era inconsistente com diversos dispositivos do Acordo SPS. Diante disso, as Comunidades Europeias apelaram do relatório do Panel, e o Órgão de Apelação teve que se manifestar sobre a aplicação do Acordo SPS.

O Órgão de Apelação afirmou que o Artigo 3 do Acordo SPS trata de três situações distintas envolvendo padrões, diretrizes e recomendações internacionais. O Artigo 3.2 determina que, na hipótese de a medida incorporar completamente esses standards internacionais, presume-se a consistência da medida com o Acordo SPS e o GATT. Já o Artigo 3.1 estabelece que, quando uma medida se baseia em um standard internacional (adota algum ou alguns de seus elementos), esta não se beneficia da presunção do Artigo 3.2, mas exige, como regra, que o Membro demandante demonstre a sua inconsistência com o Artigo 3.1 ou com qualquer dispositivo do Acordo SPS. Por fim, o Artigo 3.3 reconhece o direito de cada Membro de estabelecer seu nível apropriado de proteção, o qual pode ser mais elevado que o garantido em standards internacionais ${ }^{15}$.

Na hipótese do Artigo 3.3, em que a medida reflete o nível apropriado de proteção almejado por um Membro, o Órgão de Apelação ressalvou que este não é um direito absoluto e incondicionado. Para exercê-lo de forma regular, é imprescindível a condução de uma avaliação de risco, nos termos do Artigo 5.1, e com base em evidência científica suficiente, como requerido pelo Artigo 2.2. Nesse sentido, o Órgão de Apelação frisou que a observância desses requisitos para o legítimo exercício pelo Membro do seu direito de determinar seu próprio nível apropriado de proteção é essencial, no âmbito do Acordo SPS, para assegurar o equilíbrio entre os interesses de promoção do comércio internacional e de proteção da vida e da saúde humana ${ }^{16}$.

No que diz respeito à relevância do princípio da precaução para a interpretação do Acordo SPS, o Órgão de Apelação esclareceu que o seu status no direito internacional ainda era controverso para acadêmicos, profissionais do direito e julgadores. Por um lado, o Órgão de Apelação pontou que seria desnecessário, e até mesmo imprudente, manifestar sua opinião nesse sentido. Por outro lado, o Órgão de Apelação reputou relevante indicar que há uma

${ }^{15}$ WORLD TRADE ORGANIZATION. European Communities - Measures Concerning Meat and Meat Products (Hormones), Appellate Body Report, WT/DS26/AB/R, WT/DS48/AB/R, adopted 13 February 1998, DSR 1998:I, p. 135, par. 170-172.

${ }^{16}$ Ibidem, par. 173; 177. 
relação entre o princípio da precaução e o Acordo SPS, em particular o parágrafo sexto do seu preâmbulo, o Artigo 3.3 e o Artigo $5.7^{17}$. Contudo, o Órgão de Apelação destacou que os mencionados dispositivos não exaurem o sentido do princípio da precaução, o qual não autorizaria a adoção de medidas inconsistentes com o próprio Acordo SPS ${ }^{18}$.

A análise do Órgão de Apelação findou com a interpretação da avaliação de risco no contexto do Artigo 5 do Acordo SPS. Nesse sentido, o Órgão de Apelação recordou os termos do parágrafo quarto do Anexo A do Acordo SPS, pelo qual se extrai que a avaliação de risco compreende duas etapas: identificação de efeitos adversos para a saúde humana, caso existam, derivados dos hormônios em questão; e, caso esses efeitos existam, o potencial ou probabilidade de que eles venham a ocorrer. O Órgão de Apelação discorreu, ainda, sobre o Artigo 5.2 do Acordo SPS, que traz uma lista exemplificativa de fatores que devem ser levados em consideração para uma avaliação de risco, como evidência científica disponível, métodos de produção e processamento relevantes, condições ecológicas e ambientais relevantes, entre outros ${ }^{19}$.

Ao interpretar o Artigo 5.1, em conjunto com o Artigo 2.2, o Órgão de Apelação afirmou que o significado de uma medida baseada em uma avaliação de risco equivaleria a uma medida que encontra razoável e suficiente suporte na avaliação de risco. Tal avaliação deveria demonstrar a existência e grau de risco decorrente do uso abusivo de hormônios e as dificuldades de controle da administração de hormônios ${ }^{20}$.

Nesse contexto, o Órgão de Apelação constatou que as Comunidades Europeias não haviam realizado uma avaliação de risco, nos termos dos Artigos 5.1 e 5.2. Tal conclusão decorreu da inexistência de uma avaliação dos riscos oriundos da inobservância de boas práticas veterinárias e problemas de controle no uso de hormônios, apontados nos estudos apresentados pelas Comunidades Europeias ${ }^{21}$.

É possível constatar que o Acordo SPS, embora reconheça o direito dos Membros da OMC de determinar um nível apropriado de proteção, estabelece regras para que tal direito

\footnotetext{
${ }^{17}$ O parágrafo sexto do preâmbulo e o Artigo 3.3 do Acordo SPS reconhecem o direito dos Membros de determinar seu nível apropriado de proteção, enquanto o Artigo 5.7 do Acordo SPS autoriza a adoção temporária de medida SPS na ausência de evidência científica suficiente, excepcionalmente e desde que preenchidos alguns requisitos.

${ }_{18}$ WORLD TRADE ORGANIZATION. European Communities - Measures Concerning Meat and Meat Products (Hormones), Appellate Body Report, WT/DS26/AB/R, WT/DS48/AB/R, adopted 13 February 1998, DSR 1998:I, p. 135, par. 123-124.

${ }^{19}$ Ibidem, par. 182-183; 187.

${ }^{20}$ Ibidem, par. 193; 200; 207.

${ }^{21}$ Ibidem, par. 208.
} 
seja exercido regularmente. Como já mencionado, o embasamento científico é um dos alicerces do Acordo SPS, visto que é requisito para as medidas adotadas com a finalidade de proteger a vida e a saúde humana, animal e vegetal.

Além disso, o uso de standards internacionais é encorajado pelo Acordo SPS para fins de harmonização e legitimidade das medidas com eles conformes ou neles baseadas. Para medidas que excedam o nível de proteção dos standards internacionais, o Acordo SPS exige uma avaliação de riscos.

O Acordo SPS representa um grande avanço na regulamentação de medidas voltadas à proteção da saúde humana que afetem o comércio internacional. Enquanto o Artigo XX(b) e caput do GATT asseguram a legitimidade de políticas sanitárias diante das normas de livre comércio por meio, sobretudo, de um teste de necessidade e da forma de sua aplicação, o Acordo SPS traça critérios mais específicos para orientar o exercício regular desse direito pelos Membros da OMC. Tais requisitos, ancorados no embasamento científico e na harmonização, são essenciais para garantir que medidas sanitárias não inviabilizem de forma injustificada o comércio internacional.

\section{Conclusão}

Crises sanitárias, como esta que vivemos decorrente da COVID-19, podem significar um aumento no rigor de regras sanitárias aplicadas ao comércio sob o fundamento da necessidade de se assegurar a saúde das pessoas. A crescente adoção de medidas sanitárias pelos Membros da OMC pode representar um problema para o livre comércio internacional, uma vez que tais medidas podem disfarçar um protecionismo sob o pretexto de proteção sanitária.

Diante disso, o presente artigo buscou analisar os principais critérios estabelecidos no âmbito da OMC para averiguar a legitimidade de medidas de Membros destinadas à proteção da saúde humana. Para alcançar tal objetivo, o artigo examinou o GATT, em particular seu Artigo XX(b), e o Acordo SPS, por conterem disposições pertinentes ao estudo.

A segunda seção do artigo tratou do histórico do Artigo XX do GATT, que lista as exceções gerais às obrigações dispostas no Acordo, com base em interesses não-econômicos, mas essenciais no contexto de políticas públicas. Ainda na primeira seção, o artigo abordou o Artigo XX(b), que estabelece como uma dessas exceções a medida necessária para proteção 
da vida e da saúde humana, animal e vegetal. Segundo o entendimento do Panel na disputa EC - Asbestos, a análise acerca da compatibilidade da medida com o dispositivo depende de: (i) caracterização da medida como política de proteção da saúde e vida humana; (ii) necessidade da medida para atingir o objetivo almejado (inexistência de medida alternativa razoável compatível ou menos incompatível com o GATT); e (iii) consistência com o caput do Artigo XX do GATT, que demanda que a medida não seja arbitrária ou injustificadamente discriminatória, nem constitua disfarçada restrição ao comércio internacional.

A terceira seção do artigo abordou os principais pontos do Acordo SPS, como o histórico de sua formação e dispositivos mais relevantes. Além disso, o artigo apresentou a interpretação dessas regras do Acordo SPS conferida pelo Órgão de Apelação a partir do caso EC - Hormones. O Órgão de Apelação concluiu que: (i) o Artigo 2 do Acordo SPS requer que as medidas SPS sejam adotadas com base em evidência científica suficiente; (ii) é possível a adoção de medidas SPS sem evidência científica suficiente, em caráter excepcional e nos termos do Artigo 5.7, o que não significa que o Acordo SPS materialize o princípio da precaução; e (iii) o Artigo 3 do Acordo SPS incentiva a adoção de standards internacionais, mas autoriza que o Membro determine um nível apropriado de proteção, desde que baseado em uma avaliação de riscos, nos termos do Artigo 5.

Diante dos parâmetros expostos, é possível constatar que a OMC, em especial a partir do Artigo XX(b) e do Acordo SPS, salvaguarda o direito dos Membros de proteger interesses não-econômicos de inegável relevância, por exemplo, por meio de políticas sanitárias. Por um lado, a OMC autoriza que os Membros adotem tais medidas, ainda que venham a criar obstáculos ao livre comércio internacional. Por outro lado, essas medidas não podem possuir finalidade diversa ao objetivo legítimo que alegadamente almejam.

Sendo assim, os dispositivos e sua interpretação conferida pelo sistema de solução de controvérsias da OMC ora analisados pretendem limitar eventuais abusos no exercício desse direito por parte dos Membros. O sistema da OMC tem por finalidade promover o livre comércio, removendo barreiras discriminatórias ou protecionistas, e isso se reflete nos critérios estabelecidos para a análise de compatibilidade de políticas públicas com as regras da OMC, em particular o Artigo XX(b) do GATT e o Acordo SPS. Tais critérios são essenciais para garantir um equilíbrio entre objetivos econômicos e interesses não-econômicos, a exemplo da proteção da saúde humana. 


\section{Referências}

AMARAL JÚNIOR, Alberto do. Comércio internacional e a proteção do meio ambiente. São Paulo: Atlas, 2011.

AMARAL JÚNIOR, Alberto do (Org. e Coautor) [et al.]. O Artigo XX do Gatt, Meio Ambiente e Direitos Humanos. São Paulo: Aduaneiras, 2009.

BARROS, G.S.A.C.; BURNQUIST, H.L.; CUNHA FILHO, J.H.; MIRANDA, S.H.G. Normas sanitárias e fitossanitárias: proteção ou protecionismo. Informações Econômicas, v. 34 , n. 2, 2004, p. 25-35.

BONNOMI, Natália Paulino. O princípio da precaução no comércio internacional: confronto entre a proteção ambiental e o livre comércio. In: Eugênia Cristina Nilsen Ribeiro Barza; Francisco Antônio de Barros e Silva Neto; Paul Hugo Weberbauer. (Org.). Integração regional, globalização e direito internacional, vol. 2, 1 ed. Recife: UFPE, 2019.

GRUSZCZYNSKI, Lukasz. The Role of Science in Risk Regulation under the SPS Agreement. EUI Law Working Paper, n. 2006/03, February 2006.

KOTZIAS, Fernanda; THORSTENSEN, Vera. Barreiras regulatórias: um novo desafio para a governança da OMC. Política Externa (USP), 2015, v. 24, p. 81-92.

MARCEAU, Gabrielle Zoe; TRACHTMAN, Joel P. Map of the World Trade Organization Law of Domestic Regulation of Goods: The Technical Barriers to Trade Agreement, the Sanitary and Phytosanitary Measures Agreement, and the General Agreement on Tariffs and Trade. Journal of World Trade, 2014, vol. 48, n. 2, p. 351-432.

MOROSINI, Fabio Costa; NIENCHESKI, Luisa Zuardi. A relação entre os tratados multilaterais ambientais e os acordos da OMC: é possível conciliar o conflito?. Revista de Direito Internacional, Brasília, 2014, v. 2, n. 2, p. 150-168.

VIEIRA, Andréia Costa. A OMC e o Policy Space dos Estados: Questões de Flexibilidade, Desenvolvimento Sustentável e Políticas Públicas no GATT e no GATS. In: AMARAL JÚNIOR, Alberto do.; CELLI JÚNIOR, Umberto (Orgs). A OMC: desafios e perspectivas. São Paulo: Aduaneiras, 2014.

WORLD TRADE ORGANIZATION. Brazil - Measures Affecting Imports of Retreaded Tyres, Panel Report, WT/DS332/R, adopted 17 December 2007, as modified by Appellate Body Report WT/DS332/AB/R, DSR 2007:V, p. 1649.

WORLD TRADE ORGANIZATION. European Communities - Measures Affecting Asbestos and Asbestos-Containing Products, Panel Report, WT/DS135/R and Add.1, adopted 5 April 2001, as modified by Appellate Body Report WT/DS135/AB/R, DSR 2001:VIII, p. 3305. 
WORLD TRADE ORGANIZATION. European Communities - Measures Concerning Meat and Meat Products (Hormones), Appellate Body Report, WT/DS26/AB/R, WT/DS48/AB/R, adopted 13 February 1998, DSR 1998:I, p. 135. 